\section{Apretando las tuercas: el riego y el estado en México, 1888-1939}

\section{Tightening the Screws: Irrigation and the State in Mexico, 1888-1939}

\author{
Martín Sánchez Rodríguez \\ El Colegio de Michoacán \\ Zamora, México \\ mlobo@colmich.edu.mx \\ (iD) ORCID: 0000-0002-1969-8838
}

Información del artículo

Recibido: 06 abril 2020

Revisado: 18 febrero 2021

Aceptado: 29 marzo 2021

ISSN 2340-8472

ISSNe 2340-7743

DOI $\quad 10.17561 /$ AT.20.6052

(c) $\mathrm{CC}-\mathrm{BY}$

(c) Universidad de Jaén (España). Seminario Permanente Agua, Territorio y Medio Ambiente (CSIC)

\section{RESUMEN}

Desde la ley de aprovechamiento de aguas de jurisdicción federal de 1910 hasta la ley de aguas nacionales de 1992, hay conceptos que han permanecido vigentes o con cambios mínimos. El artículo tiene por objeto ofrecer elementos de cómo ocurre la intervención del Estado en la organización social de los regantes en una zona semiárida de México a fines del siglo XIX y principios del XX. Se trata de un trabajo histórico que analiza los reglamentos sobre los usos del agua en la primera intervención federal sobre esta materia. El estudio se centra en dos aspectos, la diferencia entre centralización y federalización y la forma en que interviene el Estado en la organización social. El trabajo aplica un nuevo enfoque al proceso de federalización del agua en México, que tiene que ver con la organización social.

PALABRAS CLAVES: México, Irrigación, Comarca Lagunera, Intervención estatal.

\begin{abstract}
From the law on the use of waters under federal jurisdiction of 1910 to the national water law of 1992, there are concepts that have remained in force or with minimal changes. The article aims to offer elements of how the intervention of the State occurs in the social organization of irrigators in a semiarid area in Mexico in the late 19th and early 20th centuries. This is a historical work that analyzes the regulations on the uses of water in the first federal intervention in this matter. The study focuses on two aspects, the difference between centralization and federalization and the way in which the State intervenes in social organization. The contribution of the work is that it applies a new approach to the process of federalization of water in Mexico that has to do with social organization.
\end{abstract}

KEYWORDS: Mexico, Irrigation, Comarca Lagunera, Government intervention. 


\section{Apertando as nozes: irrigação e estado no México, 1888-1939}

\section{SUMÁRIO}

Desde a lei sobre o uso de águas sob jurisdição federal de 1910 até a lei nacional de águas de 1992, existem conceitos que permaneceram em vigor ou com alterações mínimas. 0 artigo visa oferecer elementos de como se dá a intervenção do Estado na organização social dos irrigantes em uma zona semiárida mexicana no final do século XIX e início do século XX. Tratase de um trabalho histórico que analisa as regulamentações sobre os usos da água na primeira intervenção federal nessa matéria. o estudo centra-se em dois aspectos, a diferença entre centralização e federalização e a forma como o Estado intervém na organização social. A principal contribuição do trabalho consiste em aplicar uma nova abordagem à discussao sobre o processo de federalização da água no México privilegiando na analise a incorporação da dinamica da organizaçao social como elemento distintivo.

PALAVRAS-CHAVE: México, Irrigação, Comarca Lagunera, Intervenção do Estado.

\section{Serrer la vis: l'irrigation dans l'état de Mexico,} 1888-1939

\section{RÉSUMÉ}

Depuis la promulgation de la Loi d'exploitation des eaux de juridiction fédéral, en 1910, jusqu'à la Loi des eaux de la Nation de 1992, certains concepts ont conservé leur validité ou n'ont souffert que de changements mineurs. Le présent article a pour objet de fournir des éléments d'analyse quant à la façon dont l'État est intervenu dans l'organisation sociale des irrigants dans une zone semi-aride du Mexique, au tournant du XIXe et du XXe siècle. Il se fonde sur un travail historique d'analyse des règlements relatifs à l'usage des eaux lors de la première intervention fédérale en la matière. L'étude est centrée sur deux aspects: la différence entre centralisation et fédéralisation, et les formes d'intervention de l'État sur l'organisation sociale. Elle propose une nouvelle approche du processus de fédéralisation des eaux au Mexique, qui prête une attention particulière à l'organisation sociale.

MOTS-CLÉs: Mexique, Irrigation, Comarca Lagunera, Intervention de l'État.

\section{'Apretando las tuercas'. L'irrigazione e lo stato in Messico, 1888-1939}

\section{SOMMARIO}

Dalla Legge del 1910 sull'utilizzo delle acque federali fino alla Legge del 1992 sulle acque nazionali, ci sono concetti rimasti inalterati o che hanno subito modifiche minime. L'articolo si propone di offrire elementi sull'intervento statale nell'organizzazione sociale dell'irrigazione in un'area semiarida del Messico tra la fine del XIX e l'inizio del XX secolo. Si tratta di un lavoro che analizza in una prospettiva storica la normativa sugli usi dell'acqua nel primo intervento federale in materia. Lo studio si concentra su due aspetti, la differenza tra centralizzazione e decentramento federale e il modo in cui lo Stato interviene nell'organizzazione sociale. Il lavoro applica un nuovo approccio al processo di federalizzazione dell'acqua in Messico, incentrato sull'organizzazione sociale.

PAROLE CHIAVE: Messico, Irrigazione, Comarca Lagunera, Intervento statale. 


\section{Introducción}

"Apretar las tuercas" es una locución que significa presionar a una persona para que colabore o actúe de determinada manera tratándola con severidad o rigor. Nosotros la utilizamos para enfatizar cómo el gobierno federal pretendió incrementar su control y dominio en materia de agua en la Comarca Lagunera, una zona semiárida ubicada en los estados de Durango y Coahuila, al norte de México. Al arbitrar en la solución de los conflictos por el agua entre los regantes, el Estado, mediante la implementación de reglamentos oficiales, comenzó formalmente su intervención en la organización social antes que en otras regiones y antes de que, constitucionalmente, se le facultara para hacerlo.

Este artículo es un trabajo de corte histórico cuya fuente principal son las normas para organizar el uso del agua torrencial en una sección del río Nazas. Considero que en estos documentos se refleja bien el proceso de federalización a la hora de organizar a los usuarios de algunas corrientes. Los reglamentos analizados se elaboraron de 1895 a 1939 y dan cuenta de la forma en que el Estado intentó resolver los problemas del reparto de agua en el Nazas. Evidentemente, la intervención estatal no refleja todo el panorama mexicano, pero sí manifiesta los alcances de su intromisión.

La irrigación en los siglos XIX y XX fue uno de los paradigmas modernizadores de varios grupos sociales en diferentes partes del mundo. Con la participación de empresarios, dueños de tierra, pensadores, ingenieros y políticos, el centro del debate en general fue determinar cuál debería de ser el papel que tendría que jugar el Estado en la promoción del desarrollo económico. En el caso del continente americano, varios paises favorecieron una mayor intervención del Estado en la economía ${ }^{1}$.

Para México, la intervención del gobierno federal se comenzó a definir claramente durante el régimen de Porfirio Díaz, cuando la clase política impulsó cambios legislativos. Bajo el fundamento de la Constitución de 1857, muchos de estos cambios iban en contra del texto constitucional. Francisco Xavier Guerra afirma que la Constitución de 1857 era una "ficción legal" que sirvió de marco para implementar medidas que iban en contra de su articulado ${ }^{2}$. Para el caso que nos ocupa, un prestigioso abogado de la época, Ignacio L. Vallarta, dijo que la intervención federal para declarar como federales las vías de comunicación se había "sublevado contra el texto constitucional que ella ha querido obedecer y reglamentar"3.

Un análisis político de la historia hidráulica mexicana de finales del siglo XIX a la primera parte del XX, nos revela la importante participación del Estado si la analizamos a partir de los siguientes conceptos: federalización, centralización y nacionalización.

\section{Federalización}

Debemos de advertir que algunos autores que analizan la política hidráulica mexicana han utilizado los conceptos de centralización o federalización como sinónimos, entendidos como un proceso implementado por el gobierno central, donde hay un sometimiento o subordinación de otras instancias de poder (gobiernos locales y regionales) y de la sociedad misma, a las disposiciones legales y extralegales que provienen del gobierno central.

Desde mi perspectiva, creo que el uso de ambos conceptos como sinónimos es erróneo porque no significan lo mismo. Luis Aboites, uno de los principales autores contemporáneos que ha estudiado el papel del Estado y el de los Ayuntamientos en el manejo del agua en México, es consciente de la confusión ${ }^{4}$. En este artículo pretendemos ser más enfáticos en la distinción de ambos conceptos.

Desde mediados del siglo XIX hasta la actualidad, México ha declarado ser una República Federal constituida por estados y municipios, a quienes se concede soberanía y se les reconoce una jurisdicción territorial. En materia de aguas y en otros recursos productivos, el gobierno federal ha buscado ser el regulador. La forma de hacerlo es ampliando la jurisdicción del gobierno federal, en detrimento de las entidades que forman parte de la federación, de los municipios y de la sociedad ${ }^{5}$.

Como materia del derecho administrativo, hasta antes de 1870 el agua fue un asunto privado y formaba parte del derecho público en el ámbito local y regional. Con la expedición del Código Civil para los Territorios y el Distrito Federal en 1870 se declaró en los artículos 801 y 802 que los puertos, bahías, radas y ensenadas, ríos aunque no fueran navegables, su álveo, los ríos y esteros, lagos y lagunas que no fueran de propiedad particular, serían considerados propiedad pública y de uso común 6 .

\footnotetext{
3. Sánchez Rodríguez, 1993, 31

4. Aboites Aguilar, 1998, 11-12.

5. Aboites Aguilar, 1998.

6. Sánchez Rodríguez, 1993, 54
} 
Estas restricciones permitieron y facilitaron la intervención formal de los gobiernos estatales en la gestión de los recursos hidráulicos como se evidencia para los casos de Sonora (1843), Nuevo León y Coahuila (1857), Zacatecas (1862), Durango (1881), Jalisco (1895) y Oaxaca $(1905)^{7}$. La ausencia de restricciones en materia hidráulica desde la época colonial había dejado un amplio campo de acción para que otros actores sociales como los ayuntamientos, comunidades e incluso los particulares, tuvieran fuerte injerencia en la gestión hidráulica ${ }^{8}$. Sin embargo, a partir del segundo periodo de gobierno del general Díaz, todo fue moviéndose hacia la federalización, hacia la restricción de facultades por la fuerza de los hechos o por la vía de las leyes.

Amparado en la fracción XXII del artículo 72 constitucional que facultaba al Congreso de la Unión para dictar leyes sobre vías generales de comunicación, el 5 de junio de 1888 se aprobó la ley a partir de la cual el Estado comenzó a fijar su predominio en materia de aguas. En su artículo primero se dice cuáles eran las vías generales de comunicación ${ }^{9}$. A partir de este ordenamiento legal se inició una intensa actividad por parte de las autoridades federales, como representantes de la nación, para definir cuáles eran o deberían de ser las aguas declaradas como vías generales de comunicación; quién y dónde usufructuaban el recurso y cómo se debería de acceder al uso y explotación del mismo $^{10}$.

También se dispuso organizar la burocracia hidráulica que dependería de la Secretaría de Fomento. En la primera parte del artículo segundo de la ley de 1888 se dice: "Corresponden al Ejecutivo Federal la vigilancia y policía de estas vías generales de comunicación". Esta vigilancia se haría a partir de las concesiones o confirmaciones de los derechos a particulares de los lagos, ríos y canales que eran objeto de la ley ${ }^{11}$. En cuanto a la intervención del gobierno federal en la organización social de los regantes, correspondía al Ejecutivo Federal la facultad de reglamentar el uso público y privado de las aguas federales. Cabe advertir que esta facultad, como otras, era nueva y buscaba obligar a los regantes a cumplirlas, aunque no siempre ocurría.

\footnotetext{
7. Sandré Osorio y Sánchez, 2011. Topete Pozas y Méndez Zárate, 2019.

8. Aboites Aguilar, 1998. Castañeda, 2005. Aboites Aguilar y Estrada Tena, 2004.

9. Dublán y Lozano, 1890, tomo XIX, 153. Sánchez Rodríguez, 1993, 55. Sánchez Rodríguez, 2005.

10. El primer estudio historiográfico contemporáneo sobre este proceso es el realizado por Kroeber, 1984.

11. Dublán y Lozano, 1890, tomo XIX, 153.
}

Con el tiempo, la legislación sobre las aguas fue definiendo sus alcances. El 6 de junio de 1894 el Congreso facultó al ejecutivo para hacer concesiones a particulares y compañías con el fin de aprovechar las aguas federales en riegos y como potencia aplicable a cualquier industria ${ }^{12}$. Esta legislación fue trascendente para la apertura de nuevos espacios de cultivo de riego desecando los lagos de Chalco (1895), Zacapu (1896), Chapala (1905) y Lerma (1906), y para abrir zonas como en la Comarca Lagunera ${ }^{13}$. También fue importante para la generación de la industria eléctrica al construirse Necaxa (Puebla, iniciada en 1903), La Boquilla (Chihuahua, 1909), Jacona y El Botello (Michoacán, 1910) ${ }^{14}$.

Para mí, el concepto de federalización significa el conjunto de políticas públicas que adoptó el gobierno mexicano y sus funcionarios con el afán de consolidar un proyecto nacional. Los ejemplos de intervención federal son variados. Por ejemplo, en educación los vemos reflejados en las leyes federales de 1888, 1890 y 1891. En materia comercial el gobierno federal aprobó dos códigos de comercio, uno en 1884 y otro en 1889. Podemos seguir con la minería, la eliminación de las alcabalas, la contratación de deuda, la salubridad o, para nuestro caso, el agua.

Mientras el legislativo adecuaba las leyes con otro tipo de ordenamientos, el ejecutivo actuaba reconociendo los derechos de agua preexistentes a través de las confirmaciones, otorgando nuevos derechos mediante las concesiones, interviniendo en los conflictos por el agua en las comunidades de regantes y reglamentando los derechos de agua donde intervenía. Se trataba de un proceso lento, sujeto a múltiples presiones que, en ocasiones, encontraban bastantes resistencias y, en otras, algunas colaboraciones.

Este proceso de fortalecimiento de la federación, que se inicia durante el gobierno de Benito Juárez, tiene un punto importante durante el régimen de Porfirio Díaz y logra su máxima expresión durante los gobiernos posrevolucionarios del siglo $\mathrm{XX}^{15}$. Pero, antes de que esto ocurriera, todas las legislaciones que hemos referido tienen como fundamento la Constitución de 1857. Un texto ficticio que, según Guerra, siempre se violó en varios aspectos como el del federalismo ${ }^{16}$.

\footnotetext{
12. Dublán y Lozano, 1898, tomo XXIV, 184.

13. Sobre las desecaciones hay varios textos que se pueden consultar: Tortolero Villaseñor, 1995. Beltrán Bernal, 2017. Sánchez Rodríguez, 2013. Guzmán Ávila, 2002. Boehm de Lameiras, 1994, Boehm, 2006. Camacho Pichardo, 1998.

14. Sobre la industria hidroeléctrica deben consultarse las obras de Galarza, 1941, y Aboites Aguilar, 1998.

15. Medina Peña, 2010.

16. Guerra, 1988, 41-50.
} 


\section{Centralización}

Las modificaciones legales promovidas por el gobierno de Díaz llevaron al aumento de las competencias del gobierno federal ${ }^{17}$ y a la centralización, concepto que se desarrolla simultáneamente a la federalización. Centralizar significa que cada política pública, educativa, minera, industrial, comercial o hidráulica, es asumida por una instancia a nivel federal (Secretaría de Comercio, Agricultura, Fomento, etc.) la cual no solo fija los calendarios para las diferentes gestiones, también genera una burocracia encargada de los trámites y de la administración de los expedientes. Para el caso del agua nos referimos a la Secretaría de Fomento ${ }^{18}$.

Con la promulgación de la Ley sobre Vías Generales de Comunicación de 1888, los ayuntamientos, comunidades de regantes y algunos gobiernos de los estados fueron perdiendo facultades legales para conceder derechos, hacer labores de policía (vigilancia) y administrar las aguas federales dentro de sus jurisdicciones, no sin antes oponer resistencias ${ }^{19}$. Y fueron precisamente las resistencias que ofrecieron los municipios y las comunidades de regantes las que provocaron que Luis Aboites publicara un texto cuestionando su idea sobre la centralización y/o federalización $^{20}$.

Aboites afirma que "La investigación empírica deja ver que en diversos lugares la nación no sólo era omitida o ignorada, sino también subordinada y maniatada"21. Mi perspectiva es distinta. Parte de dos consideraciones. La primera es que antes de 1888, el gobierno federal, como representante del Estado nacional, no tenía injerencia en la gobernanza del agua. Esta era asumida básicamente por los ayuntamientos y las comunidades de regantes ${ }^{22}$. Después de 1888 la cosa cambió. Con o sin resistencia, comenzamos a ver la intervención federal en los procesos de dotación, confirmación, reparto, vigilancia, conservación, construcción, control, ingresos o impuestos, justicia y

\footnotetext{
17. Guerra, 1988, 50 .

18. Zuleta, 2000.

19. Algunos ejemplos se muestran en las obras de Kroeber, 1994. Sánchez Rodríguez, 1993. Aboites Aguilar, 1998.

20. Aboites Aguilar, 2009.

21. Aboites Aguilar, 2009, 10.

22. Los estados que legislaron antes de 1888 fueron Sonora, Nuevo León, Coahuila, Zacatecas y Durango. Véase la nota 7.
}

equidad en los sistemas de riego como parte del dominio que trata de imponer el gobierno federal ${ }^{23}$.

La segunda consideración tiene que ver con el poder, entendido este como la posibilidad que tiene una persona para encontrar obediencia a partir del control que se ejerce sobre partes del ambiente que les interesan a otros sujetos. El control forma parte del proceso físico de manipular energéticamente los elementos de la naturaleza. Por lo tanto, la centralización y federalización son consecuencia del ejercicio del poder a partir del control que se tiene sobre los recursos legales, armados, financieros, políticos y naturales, siendo reconocido por los particulares ${ }^{24}$.

Volviendo a nuestro tema, a partir de la política de centralización se fue desarrollando el proceso de federalización al dotar a la Secretaría de Fomento de un equipo humano especializado que constituyó la burocracia hidráulica ${ }^{25}$. También se comenzó a ordenar el proceso que deberían de seguir los regantes para obtener una concesión o confirmación de los derechos de agua de jurisdicción federal en el reglamento de la primera ley de aguas federales de $1910^{26}$.

De este reglamento se deduce una pretendida organización racional de los asuntos manejados por la burocracia: integración de un inventario de las corrientes federales y la relación de los usuarios que gozaban de derechos de agua. Como consecuencia de lo anterior, el control del recurso agua se fue afinando y, en teoría, se podría administrar eficientemente. De esto último no estamos tan seguros pues los intereses personales expresados en la toma de mayor flujo de agua de la concedida, los despojos de derechos y otros procesos, marcan la diferencia entre la ley y la práctica cotidiana.

Sin embargo, para los fines de un control político administrativo, la práctica seguida por la Secretaría de Fomento era más operativa para el Estado. Por ejemplo, a partir de los expedientes se podía contar con historiales particularizados; hacer un padrón de usuarios, determinar (formalmente) las cantidades de aguas aprovechadas. Esto, unido al estudio técnico de los flujos y

\footnotetext{
23. Sobre el dominio y las relaciones de dominación me baso en las obras de Max Weber y Barrington Moore. Para el primero, el dominio es la posibilidad de encontrar obediencia a un mandato determinado y es legitimado siempre y cuando sea socialmente aceptado, de lo contrario, si hay resistencia, la relación de dominio se convierte en una relación de poder que no es voluntaria. La dominación socialmente legítima permanece siempre y cuando dominados y dominadores cumplan los derechos y deberes, límites y obligaciones que se originan cuando se establece la relación de dominación. Weber, 1983, 43, 170. Moore, 1989, 30.

24. Adams, 1983.

25. Boletín, 1909, I, XXIV-XXV.

26. Ley de aprovechamiento, 1910.
} 
las necesidades hidráulicas, permitió determinar si se concedía o no nuevos derechos o podrían servir para planear la infraestructura.

Un trabajo de tal naturaleza implicó un "eficiente" aparato burocrático especializado. Este había encontrado un lugar en la Quinta Sección de la Secretaría de Fomento, que empezó a funcionar a partir de 1888. Posterior a ese año, la burocracia hidráulica no dejó de crecer hasta que se crea la Secretaría de Recursos Hidráulicos cinco décadas más tarde.

\section{Nacionalización}

Anteriormente comenté que la Constitución del 1857 era una "ficción legal" y que en diferentes momentos se realizaron acciones legislativas que iban en contra de su doctrina, este es el caso de la nacionalización. La Ley de Vías Generales de Comunicación de 1888 se inscribe en este punto y esta contradicción legal se resolvió en la Constitución del $1917^{27}$ (Tena Ramírez, 1982, 817-880). Por tanto, el concepto de nacionalización para tierras y aguas se entiende a partir de la potestad que tienen los Estados soberanos para asumir o recobrar la explotación de bienes o el desarrollo de actividades que se consideren de interés público y que estaban sujetas a la acción de los individuos ${ }^{28}$.

Para que al Estado nacional le sea reconocida la soberanía de asumir o recobrar la explotación de bienes o el desarrollo de actividades es importante que cuente y se le reconozca el dominio eminente de los recursos por parte de la sociedad. En el caso del agua, antes de la Ley de 1888 , los sistemas de riego desplegados en México, por lo menos desde la colonia, se habían desarrollado bajo un largo proceso de patrimonialización, o de apropiación del dominio eminente de tierras y aguas por parte de los regantes. La recuperación de los derechos de la Nación sobre los derechos privados es uno de los aportes de la Constitución de $1917^{29}$. ¿Qué entendemos por el concepto de patrimonialización en nuestro tema?

\footnotetext{
27. En la discusión y definición del artículo 27 de la Constitución de 1917 se distinguen dos puntos de vista respecto a los alcances de la nacionalización que, al final, se articularon en la redacción final. Por un lado, está la posición de Andrés Molina Enríquez, quien afirmó que la nación tenía el derecho pleno sobre tierras y aguas y podía otorgar el dominio directo a los particulares. Diferente fue la posición de los diputados liderados por Pastor Roauix, quienes sostuvieron que los recursos del subsuelo no se trasmitían a particulares. Córdova, 1982, 223-230. Ovalle Favela, 2007.

28. Serra Rojas, 1977, 296-298. López Guardiola, 2012, 73-74.

29. Córdova, 1982, 226.
}

Desde los primeros siglos medievales, las aguas fueron consideradas como bienes personales o patrimoniales, sujetas al dominio eminente del soberano y, en consecuencia, al derecho de disponer de él. Como parte de la soberanía del poder regio, el agua podía ser objeto de cesión, donación o alienación de dominio. Esta soberanía, aplicada sobre una población, un territorio y los recursos naturales a través del domino eminente en la Nueva España, fue asumida por la Corona. Este dominio eminente, que en un principio correspondía al soberano, también incluía a los señores feudales e incluso a las comunidades municipales. La propiedad eminente de los señores coexistía con la propiedad útil, la cual podía ser retenida por los dueños eminentes o cedida a los particulares o a los pueblos ${ }^{30}$.

La naturaleza especial del agua, a diferencia de la tierra y del bosque, dificulta o impide un disfrute absoluto del recurso. Cada vez que dos o más personas forman una comunidad de regantes $\mathrm{y}$, por lo tanto una asociación de riego, las diferencias o desacuerdos generan un conflicto y la necesidad de solucionar estos desacuerdos tiene una larga trayectoria. Para solucionar estos apremios las alternativas son variadas. Se puede utilizar la fuerza pero también la solución puede venir de la autocomposición, es decir, mediante el acuerdo entre ambas partes. Finalmente está la intervención mediante la cual el Estado tiene a su cargo dirimir imparcialmente las diferencias entre sus miembros ${ }^{31}$. A esta actividad de solucionar los problemas por parte del Estado se le denomina jurisdicción y durante varios siglos el titular de la jurisdicción era el monarca, quien delegó sus funciones a oficiales y funcionarios hasta la revolución francesa y la separación de los tres poderes: ejecutivo, legislativo y judi$\mathrm{cial}^{32}$.

En términos de la organización social para el riego, los que tienen derecho a regar se agrupan en dos tipos de asociaciones: las públicas y las privadas. En las públicas el derecho de agua se asigna a los ayuntamientos o pueblos. El común denominador es que la organización social aparece claramente dirigida por una autoridad política con un acotamiento importante: esta autoridad es local o regional y en varios casos se luchó para que así permaneciera, incluso hasta el siglo XX. En el ámbito de sus funciones, la autoridad concede o

\footnotetext{
30. Maluquer de Motes, 1985. Sobre el dominio eminente en México durante la conquista y el periodo colonial en cuanto a los encomenderos y a la población indígena, puede verse el trabajo de García Martínez, 1992.

31. Huesbe Llanos, 1995, 337.

32. Huesbe Llanos, 1995, 342-343.
} 
legitima derechos de agua, vigila el reparto, construye o mantiene la red hidráulica, restringe su uso, intermedia y resuelve conflictos, cobra derechos de uso y maneja a los operadores del riego. En otras palabras, ejercen de hecho el dominio eminente del recurso agua $^{33}$.

En el caso de las privadas, el derecho al agua se asigna a personas, sin intervención de autoridades; y las funciones de trasmisión de estos derechos ocurren a partir de una venta o renta de agua. También la construcción, vigilancia, mantenimiento y cobro corresponde a los miembros de la asociación y solo en la resolución extrema de controversias se acude a una instancia oficial ${ }^{34}$.

La incapacidad de control por parte de la Corona o sus representantes, así como la imposibilidad de los gobiernos nacionales, fue generando un sentido de propiedad de los recursos naturales por aquellos que los usaban. Es decir, del dominio útil que tenían los regantes de los recursos se fue pasando al desarrollo del dominio eminente de los mismos. Esto desencadenó un proceso de patrimonialización que la Constitución del 1857 legitimó. Córdova lo dice así: "la sociedad había perdido su derecho originario y unos pocos individuos la habían sustituido en una función que para ella era vital" 35 .

En síntesis, con la llegada de la ley federal de 1888 el gobierno central comenzó a rescatar el dominio eminente y la jurisdicción a través de dos formas: la concesión y la confirmación. Se trata de un proceso largo y con muchas resistencias que se fue desarrollando poco a poco a partir de las nuevas necesidades que estaban generando el agua o la política de irrigación; o de los conflictos entre los regantes que no habían podido ser solucionados en instancias locales.

Pero la Ley de Vías Generales de Comunicación, en términos jurídicos, era ilegal. Un ministro de la Suprema Corte de Justicia de la Nación afirmó categóricamente que "estas declaraciones, lo mismo que otros varios preceptos de esta ley, se ha sublevado contra el texto constitucional que ella ha querido obedecer y reglamentar" ${ }^{\prime 3}$. También afirmaba que eran los gobiernos locales los facultados para la concesión o confirmación de ríos y tierras que estuvieran en una misma

\footnotetext{
33. Una compilación sobre las asociaciones públicas se encuentra en Sandré Osorio y Sánchez, 2011.

34. Para una discusión teórica ver los capítulos que se agrupan en el libro de Martínez Saldaña y Palerm Viqueira, 1997.

35. Córdova, 1982, 226.

36. Vallarta, $1897,9$.
}

entidad federativa. Hacer lo contrario significaba que la federación se había sublevado "contra el código fundamental, dando a la federación facultades, que se reservó a los estados" ${ }^{37}$. Otro autor, Andrés Molina Enríquez, afirmó lo absurdo de estas leyes: "Como se ve, todas esas leyes forman un conjunto de absurdos jurídicos, y como es natural, la jurisprudencia formada con las concesiones que de esa legislación se han derivado, es todavía más absurda" ${ }^{38}$.

Pero ninguna crítica pudo evitar la aplicación de la ley de $1888 \mathrm{ni}$ la ley de aguas de 1910. Tuvo que llegar el movimiento armado conocido como revolución mexicana para que en el texto constitucional de 1917, en su artículo 27, se legalizara para la nación el dominio eminente del agua ${ }^{39}$.

\section{Federalización de la organización social}

Este concepto lo comenzamos a ver claramente en el artículo segundo de la ley de 1888, que faculta a la Secretaría de Fomento a encargarse de la vigilancia y policía de las vías generales de comunicación. Desde mi perspectiva, la "policía" significaba que correspondía al Ejecutivo Federal la autoridad de reglamentar el uso público y privado de las aguas federales. Pero esta potestad tendría que ser bajo la dirección de un burócrata o de una persona que va a tratar de acatar y de responder, en teoría, a los dictámenes de la Secretaría de Fomento. Esta intervención del gobierno federal era una facultad nueva que se fue mejorando con el paso del tiempo y que trataba de obligar a los regantes a cumplirla, aunque no siempre ocurría ${ }^{40}$.

La federalización en la organización social es el reconocimiento de una legalidad formal que hace el Estado y que depende de tres situaciones. Por un lado, de los reglamentos de agua que mantenían las comunidades de regantes y que en algunos casos venían desde la época colonial y que fueron adoptados parcialmente por el

\footnotetext{
37. Vallarta, $1897,9$.

38. Molina Enríquez, 1978, 260.

39. Tena Ramírez, 1982, 825. Es pertinente aclarar que el artículo 27 que se refiere a la propiedad originaria de la nación refleja dos intenciones en la exposición de motivos y en sus artículos. La que se refiere a la propiedad originaria de la nación sobre la tierra y agua es producto de Andrés Molina Enríquez. La que tiene que ver con los minerales y substancias del subsuelo es de Pastor Rouaix y los diputados de la comisión. En la segunda se impedía que el dominio directo o propiedad de la nación pudiera transmitirse a los particulares. Ovalle Favela, 2007, 174-178.

40. Así lo demuestran los trabajos de Martínez Saldaña y Palerm Viqueira, eds. 1997, y Aboites Aguilar, 2009.
} 
gobierno federal ${ }^{41}$. Por otra parte, de los acuerdos de hecho que los regantes mantenían y que fueron oficializados por el Estado cuando se dio la declaración federal del río y sus afluentes ${ }^{42}$. Algunos de estos acuerdos también provenían del periodo colonial. Finalmente, de los reglamentos que se realizaron en las nuevas tierras de riego inaugurados por la política de irrigación del porfiriato y de los gobiernos de la revolución ${ }^{43}$.

La federalización organizativa, como la centralización y la nacionalización, fue un proceso también iniciado a partir de corrientes que fueron declaradas como federales: Nazas, Atoyac, Duero, Nexapa, Cantarranas, Turbio, San Juan del Río, Lerma, Yaqui, Magdalena, etcétera $^{44}$. Conforme la burocracia y los conflictos por las aguas aumentaron en otras corrientes, muchos ríos, lagunas y arroyos fueron declarados también federales y sujetos a la legislación federal y su organización social comenzó a intervenirse. Para algunos académicos este asunto aún no ha terminado y todavía en el siglo XXI se siguen documentando descripciones etnográficas de organizaciones sociales que han resistido con cierto éxito o donde de plano el Estado no ha podido intervenir ${ }^{45}$.

Las disposiciones legales sobre la federalización del agua de 1888, 1894, 1902, 1908, 1910, 1926, 1929, 1934, 1942 y 1952 fueron eslabones o mecanismos de control social que condicionaron muchos aspectos de la gestión del agua con más o menos resultados. Por ejemplo, en 1894 los regantes con aguas de jurisdicción federal, que antes de 1888 se arreglaban en lo privado o acudían a las autoridades locales para vender, comprar, hipotecar, acceder y vigilar los derechos de agua; construir, mantener, mediar en el conflicto, etcétera, después de 1894 no solo tenían que solicitar la concesión de derechos al gobierno federal, también tenían que admitir el nombramiento de un inspector ${ }^{46}$.

Recordemos que durante siglos las tareas siempre presentes en los sistemas de riego estuvieron dominadas por las comunidades de regantes y gobiernos locales. No es casual que los primeros ejemplos de intervención federal hayan sido precisamente en las zonas que presentaban problemas entre los regantes: La Comarca Lagunera (Du-

\footnotetext{
41. Un trabajo general sobre los reglamentos es el de Palerm et al., eds. 2004.

42. Es el caso, por ejemplo, de los reglamentos de los sistemas de riego del valle de Celaya. Sánchez Rodríguez, 2005.

43. Palerm et al., eds. 2004.

44. Kroeber, 1994.

45. Ver los textos publicados por Martínez Saldaña y Palerm Viqueira, eds. 1997. Palerm Viqueira y Martínez Saldaña, eds. 2000. Palerm Viqueira y Martínez Saldaña, eds. 2013. Aboites Aguilar, 2009.

46. Dublán y Lozano, 1898, t. XXIV, 180.
}

rango y Coahuila), el valle de Atlixco (Puebla), el valle de Zamora (Michoacán) y el Bajío ${ }^{47}$.

Varias de estas comunidades privadas tenían un reconocimiento de facto pero no de jure; es decir, no tenían una constitución formal mediada por el reconocimiento de una autoridad política (ayuntamiento o gobierno regional); su distribución del agua estaba bien establecida en las prácticas cotidianas pero se hacían sentir solo cuando sus intereses eran afectados o cuando la cohesión interna no era lo suficientemente fuerte como para controlar el conflicto, debiendo recurrir a una instancia de mediación, como aconteció con la Real Audiencia durante la colonia, o el Poder Judicial durante el México independiente ${ }^{48}$. Por el contrario, las comunidades públicas estaban más vinculadas a una estructura corporativa. Por lo que respecta a las acciones legales durante el porfiriato, solo fueron la preparación del terreno para lo que harían los gobiernos de la revolución.

\section{¿Qué pasó en una zona semi árida como La Comarca Lagunera?}

En el centro del país, la infraestructura hidráulica, y por lo tanto la organización social para el riego, contaba con una larga historia que provenía del mundo prehispánico. En el Bajío su infraestructura de riego también fue construyéndose y desarrollándose desde el siglo XVI. Por el contrario, en la Comarca Lagunera los sistemas hidráulicos y la organización social tenían un origen muy tardío debido a que la tierra había permanecido inculta y dedicada principalmente a la ganadería hasta la primera mitad del siglo XIX.

Con escasa población permanente y atacada por las tribus semi nómadas, la Laguna se integró al esquema de la propiedad colonial a través del latifundio de los marqueses de Aguayo. Un acaparamiento de recursos que fue iniciado por Francisco de Urdiñola y sucesores, quienes lograron una exitosa combinación de empresas 
mineras, agrícolas y ganaderas repartidas entre los actuales estados de Zacatecas, Durango y Coahuila ${ }^{49}$.

El acaparamiento de tierras y aguas no solo correspondió a Urdiñola y a los marqueses de Aguayo. En el siglo XVII también se erigieron otras grandes propiedades. Pero, al iniciarse el siglo XIX estos grandes latifundios comenzaron a dividirse en fracciones cada vez más pequeñas, en especial, las tierras del marquesado de Aguayo que por demanda de sus acreedores terminaron divididas en 50 predios $^{50}$ (Mapa 1).

Uno de los beneficiarios de esta división fue José Miguel Sánchez Navarro quien en 1818 adquirió la hacienda de San Lorenzo de La Laguna ${ }^{51}$. Por espacio de treinta años los Sánchez Navarro controlaron la comarca hasta que vendieron su propiedad el 24 de abril de 1848 a los socios Leonardo Zuloaga y José Ignacio Jimé-

Mapa 1. Propiedades en la Comarca Lagunera. Fines del siglo XIX

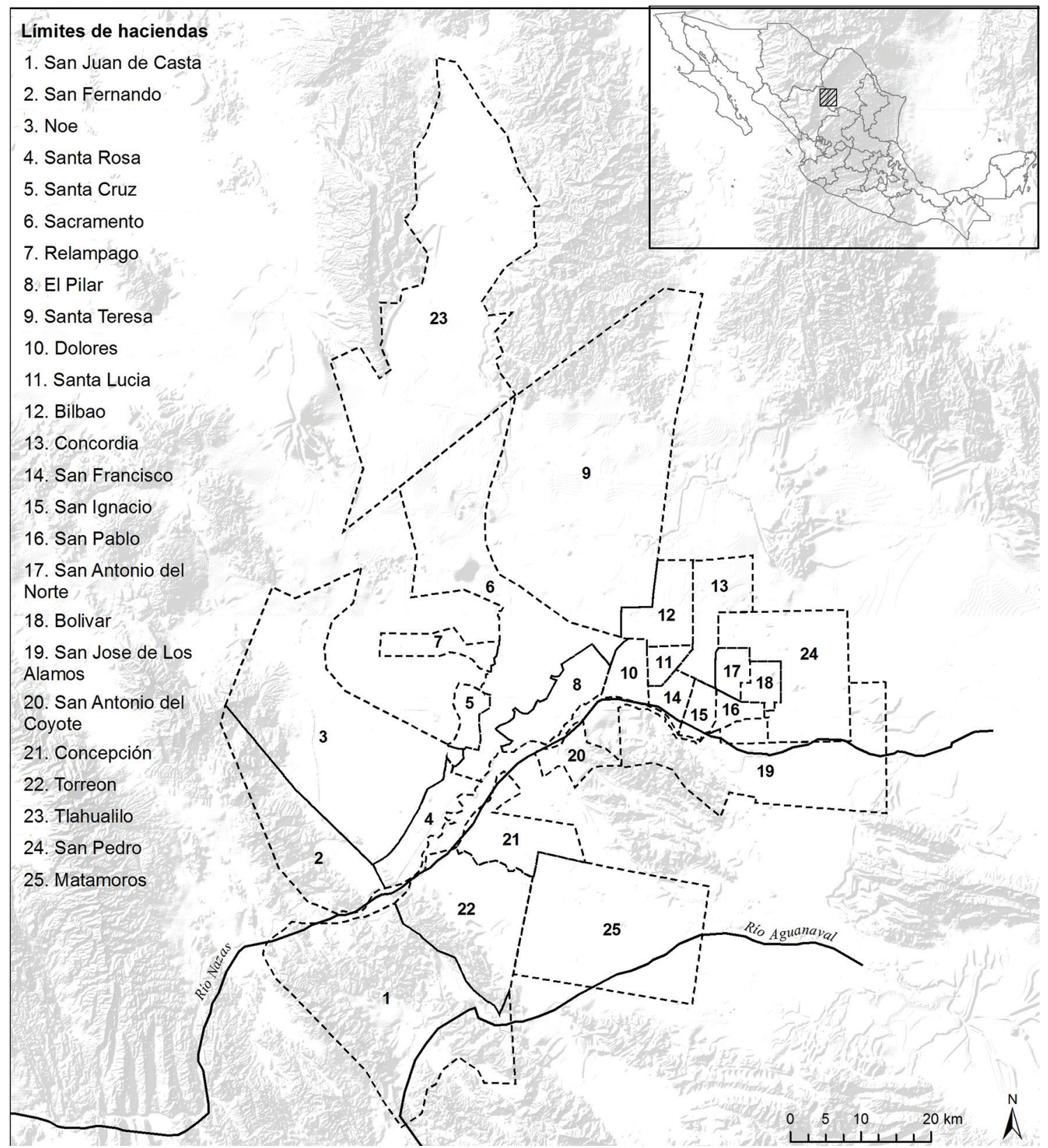

Fuente: Plana, 1996, Archivo Histórico Municipal de Torreón, Fondo Tlahualilo, Exploración del río Nazas, caja 1, exp. 1. Elaboró Marco Antonio Hernández A., COLMICHSIG. 
nez. En síntesis, desde el siglo XVII hasta el año de 1848 la infraestructura para el riego pertenecía a un solo propietario: los marqueses de Aguayo. Posteriormente, a los Sánchez Navarro.

Pero el desarrollo agrícola de La Laguna tiene una fecha crucial y es el año de 1848 cuando los propietarios en ambas márgenes del río Nazas comenzaron a incrementar los sistemas hidráulicos. Con el fraccionamiento de los latifundios, el recurso hídrico fue cada vez más competido y la organización social del riego comenzó a complejizarse. Pronto, el uso del agua se convirtió en uno de los principales motivos de discordia por el régimen torrencial del río Nazas y la falta de acuerdo de cómo y cuándo repartirse ${ }^{52}$.

Hasta el año 1846 el primer sistema hidráulico construido fue integrado por dos regantes, los dueños de San Lorenzo de la Laguna (Zuloaga y Jiménez) y su vecina San Juan de Casta. Este sistema se componía de tres presas, la correspondiente a San Juan, la de San Fernando y la de Santa Rosa. Con la venta y división de la hacienda de San Lorenzo de la Laguna en dos fracciones en 1852, la comunidad de regantes estuvo formada por tres propietarios y cada propietario contaba con una presa y sus respectivos canales ${ }^{53}$.

Para la década de 1870 los regantes se incrementaron por las ventas que hicieron los descendientes de Juan Ignacio Ramírez y Leonardo Zuluaga; así como por la fundación de las villas de Matamoros y San Pedro con las tierras incautadas por Benito Juárez ${ }^{54}$.

El cultivo del algodón a mediados del siglo XIX provocó que el agua, al igual que la mano de obra, pronto se convirtiera en un foco de tensiones donde la ubicación de las tierras de riego, los volúmenes de agua controlados y la incorporación de nuevos usuarios fueron motivo de conflicto permanente, antes y después del control federal del agua ${ }^{55}$.

Hasta antes del Reglamento de 1891, que fue el expedido por la Secretaría de Fomento debido a los conflictos suscitados entre los usuarios, la gobernanza del agua se regulaba por las prácticas cotidianas; no había

\footnotetext{
52. Plana, 1996, 53.

53. En un párrafo anterior comenté que el uso del agua dificulta o impide, en algunos casos, un disfrute absoluto del recurso pues cada vez que dos o más personas forman una agrupación, surgen a menudo las diferencias, lo que genera el conflicto por la resistencia de una parte a la pretensión de la otra. De esta forma, la unión de dos o más regantes que comparten un sistema de riego, constituye una comunidad de regantes que debe ponerse de acuerdo para no generar conflictos. Huesbe Llanos, 1995, 337. Martínez Saldaña y Palerm Viqueira, eds. 1997.

54. Archivo Histórico del Agua (AHA), Aprovechamientos Superficiales, caja 256, expediente 2492, legajo 6

55. Saravia, 1909, 4-5. Romero Navarrete, 2007, 50.
}

un reglamento sancionado y aprobado por los usuarios del agua (Mapa 2). Eran sistemas de riego sin estructuras de autoridad constituida y mucho menos centrali$z \mathrm{zda}^{56}$. A diferencia de los casos de Valencia, España, pero semejante a lo que ocurría en el Bajío, el manejo del agua en el río Nazas tampoco derivó en un reglamento que especificara los deberes y obligaciones en los sistemas de riego. Esto no significa la ausencia de una organización social ${ }^{57}$.

Tenemos el caso del reglamento de un canal que derivaba agua del río Nazas. Se trata de un documento protocolizado en la Villa de San Pedro el 22 de marzo de 1876. Sabino Gutiérrez -como presidente nombrado por los accionistas del canal o tajo de La Trasquilapresenta el reglamento, que fue consensuado entre los accionistas el primero de marzo de $1876^{58}$.

El documento refleja que la construcción del canal fue iniciativa de varios socios. Por acuerdo se dispuso que cuando llegaran las avenidas del río, y para evitar fricciones entre los miembros, se contrataría a una persona para que se encargara de dar a cada regante el agua que le correspondía de acuerdo con el presidente de la asociación ${ }^{59}$. Aunque el documento tiene que ver casi exclusivamente con la construcción de infraestructura hidráulica, la participación de una autoridad política local o regional está ausente. Esta autonomía cambiaría quince años después con el reglamento federal de 1891.

El Nazas fue el primer río donde la federación intervino antes de que el Legislativo promulgara la Ley General de Vías de Comunicación del 5 de junio de 1888. La conflictividad por el cultivo del algodón y el enfrentamiento entre los gobiernos de Durango y Coahuila por proteger el derecho de sus habitantes, provocó la intervención del gobierno central ${ }^{60}$.

Pero el conflicto más fuerte fue cuando la Compañía Agrícola del Tlahualilo, fundada en 1885, solicitó al gobierno federal autorización (abril de 1887) para abrir un canal en los territorios controlados por la Compañía, es decir, en el estado de Durango. Esto provocó la protesta de los regantes y del gobierno de Coahuila. Antes de otorgar este permiso, el secretario de Fomento integró una comisión de expertos que evaluaría la factibilidad de la concesión. Esta comisión debería de proporcionar

\footnotetext{
56. Hunt, 1997.

57. Glick, 1988. Maass y Anderson, 1976. Ostrom, 2011.

58. AHA, Aguas Nacionales, caja 256, exp. 2492, f. 212.

59. AHA, Aguas Nacionales, caja 256, exp. 2492, f. 214.

60. Rouaix, 1929, 195-197.
} 
Mapa 2. Sistemas de riego en la margen izquierda del río Nazas. Fines del siglo XIX

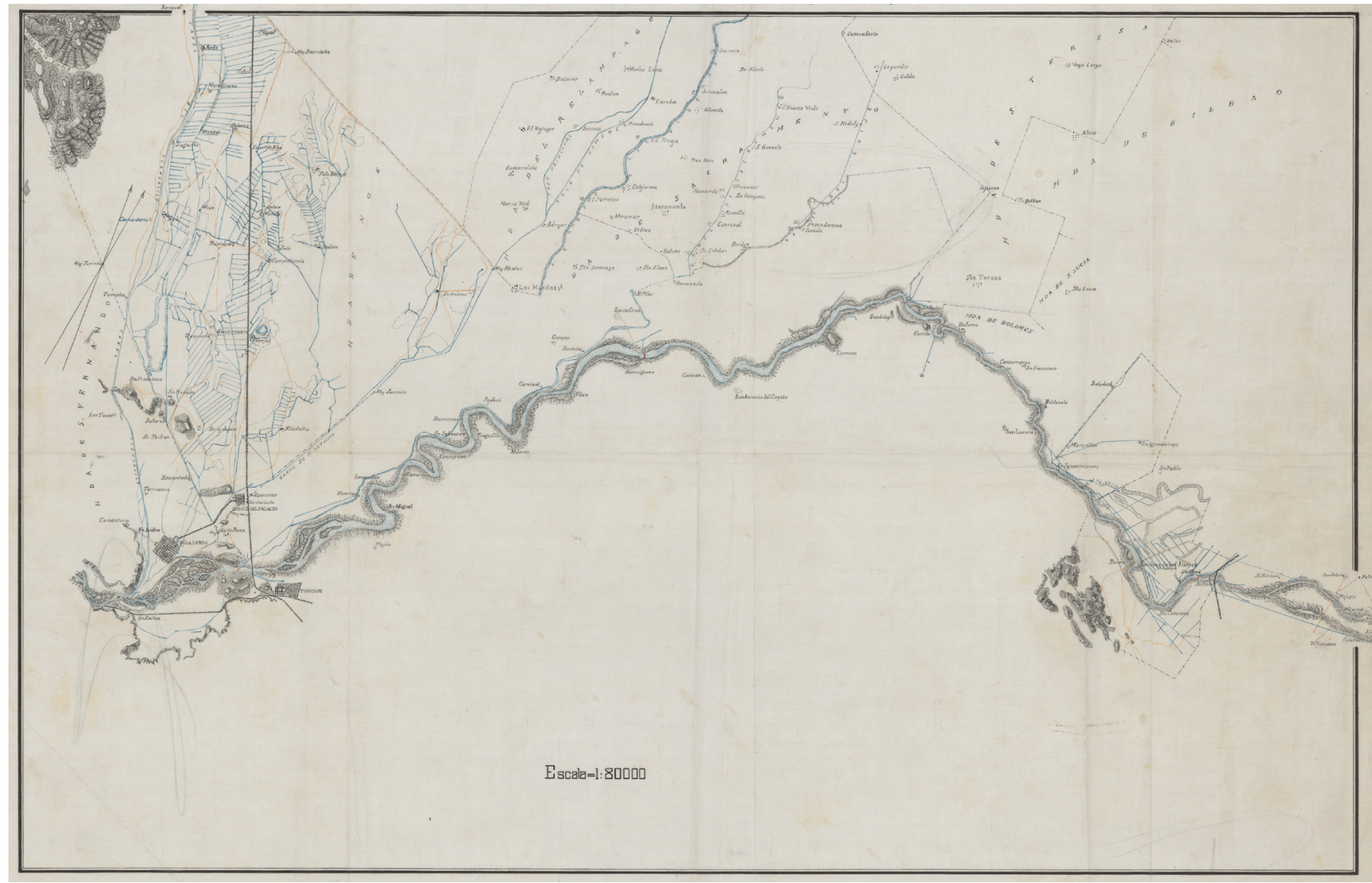

Fuente: Mapoteca Manuel Orozco y Berra, Colección General, Coahuila, exp. Coahuila 2, CGF.COAH.M4.42.0073-1-2

una base científica, razonada y demostrable, que permitiera una distribución equitativa de las aguas ${ }^{61}$.

Parte del resultado fue saber quiénes eran los regantes, cuál era su base legal. Cuál era el régimen anual del río, las condiciones físicas de las obras de irrigación, las aguas que captaban en años buenos y malos ${ }^{62} \mathrm{y}$, por último, la formulación de un reglamento, en principio provisional, en donde se colocaba al gobierno central como regulador de la organización social del agua. En síntesis, los conflictos "pusieron en evidencia que los acuerdos tácitos habían dejado de funcionar como una vía para resolver las disputas"

En sus inicios, la primera comisión formada por la Secretaría de Fomento estuvo integrada por representantes de los gobiernos de Durango y Coahuila, la Secretaría y la Compañía del Tlahualilo. Pero, a partir de 1888 se creó la Comisión del Nazas como parte de la Secreta- ría de Fomento que reelaboró el documento provisional de 1891 y promulgó otro en $1895^{64}$.

El reglamento transitorio de 1891 constaba de 28 artículos. Involucró a los propietarios ribereños que usaban siete presas (San Fernando, Santa Rosa, Calabazas, Torreón o Coyote y San Pedro, así como otras dos derivaciones) y 29 canales. Estos ribereños deberían de obedecer las órdenes de un ingeniero inspector, pagado por los interesados, pero bajo el mandato de la Secretaría de Fomento. También sería obligación de los regantes establecer el origen de sus tomas y los dos primeros kilómetros del canal ${ }^{65}$.

El mantenimiento también era vigilado por el personal de la Secretaría ${ }^{66}$. Los artículos 13, 25 y 26 son claros en términos de la federalización. En ellos se afirma de manera categórica que ninguna obra, ya sea en las orillas, ya sea en el cauce del río, ni toma de agua, ni

\footnotetext{
61. Kroeber, 1994, 115-117. Romero Navarrete, 2007, 68-70.

62. Kroeber, 1994, 119

63. Romero Navarrete, $2007,67$.
}

\footnotetext{
64. Reglamento Provisional, 1891. Sarabia, 1909, 239-266.

65. Reglamento Provisional, 1891, 4.

66. Reglamento Provisional, 1891, 6.
} 
presa, ni puente, podrán ser emprendidos sin previa autorización de la Secretaría de Fomento. En el artículo 25 se afirma que la Secretaría nombraría un ingeniero inspector con ayudantes pagados por el Tesoro Federal, siendo deber de dicho ingeniero tratar de hacer cumplir el reglamento ${ }^{67}$. No obstante el control estatal, en el artículo 27 se daba la oportunidad de que los usuarios pudieran hacer cumplir el reglamento a través de un sindicato. Pero esta situación nunca se dio.

Esta norma fue provisional. Después de múltiples conflictos por el acceso al agua entre los diferentes usuarios y la intervención de inspectores de la Comisión del Río Nazas, el gobierno federal logró consensuar una disposición definitiva en 1895. Lo importante del reglamento provisional y el definitivo de 1895 fue la intervención de los inspectores de la Secretaría de Fomento, no solo para el estudio de la conflictividad y las alternativas de solución, sino para imponer la visión de que sería el gobierno federal el encargado de reglamentar las aguas que habían sido declaradas como de jurisdicción federal. Es decir, todos los usuarios deberían de reconocer las disposiciones del gobierno federal.

El reglamento de 1895 estaba compuesto por 46 artículos. Destaca la presencia de la Secretaría, que se coloca, por efectos de la ley de agua de 1888 , como administradora de las aguas del rio Nazas y afirma, en el artículo tercero, que se conservará el curso actual del río por medio de obras autorizadas por la propia Secretaría. En otros artículos se especifica cómo la Secretaría determinó las obras de derivación de los canales especificando que el ingeniero inspector las revisaría antes de darles el visto bueno ${ }^{68}$.

Lo que nos interesa en este artículo es lo relacionado al artículo 25. En esta fracción se ordena que la Secretaría nombrará un ingeniero inspector y sus ayudantes pagados por el tesoro federal ${ }^{69}$. Este aspecto es importante en virtud de que en las organizaciones privadas el personal estaba bajo los mandos de los regantes, quienes administraban el recurso agua. La única posibilidad que tenían los usuarios del agua del Nazas fue la de contratar a un guarda compuerta, es decir, a la persona que estaría atenta a las órdenes de los funcionarios federales. La función de los propietarios y, en su caso, de los arrendatarios, medieros o personas encargadas de las fincas era dar aviso al ingeniero en jefe de la Comisión

\footnotetext{
67. Reglamento Provisional, 1891, 15-17.

68. Reglamento, 1919, 7.

69. Reglamento, 1919, 22.
}

Inspectora del Nazas de quién sería el guarda compuerta y el lugar de su residencia ${ }^{70}$.

En 1919 se realizaron modificaciones al reglamento de 1895 pero en el tema que nos ocupa no hubo cambios $^{71}$. Después de la pacificación del país a fines de 1920, de la creación de la Comisión Nacional de Irrigación en 1926 y de la creación de los distritos de riego, el Estado mexicano promulgó otros reglamentos. Resulta interesante analizar el reglamento de 1939 porque en este punto se promueve la organización de los usuarios en Juntas Locales de Agua como cooperantes para la aplicación del reglamento. En estas juntas deberían de tener participación no solo los ejidatarios, sino también se incluyó a los usuarios públicos y domésticos y a los pequeños propietarios. Las obligaciones de los usuarios eran varias; iban desde nombrar a sus representantes, contribuir en los gastos de administración y distribución de las aguas; en la conservación y en el mantenimiento de la infraestructura hidráulica ${ }^{72}$. En el artículo 60 se define, de manera categórica, que la única autoridad responsable para la aplicación del reglamento era la Comisión Nacional de Irrigación representada por el gerente general del distrito de riego de la Región Lagunera $^{73}$. Pero lo más importante para nuestro problema de la federalización tiene que ver con lo que afirma el artículo siguiente (el número 61):

“Todo el personal necesario empleado para la aplicación interna de las disposiciones de este Reglamento dependerá directamente del Distrito de Riego de la Región Lagunera, a quien compete designarlo, así como atender todo lo que a cada canal se refiera; en la inteligencia de que los gastos que dicho personal cause, serán erogados por los Usuarios del mismo canal, en la proporción en que se encuentren entre sí los terrenos reconocidos como de riego en dicho Canal" ${ }^{74}$.

En síntesis, a los usuarios solo les correspondió cubrir los costos del riego.

\footnotetext{
70. Reglamento, 1919, 24.

71. Modificaciones al reglamento, 1919

72. Reglamento, 1939, 2-7.

73. Reglamento, 1939, 25.

74. Reglamento, 1939, 25.
} 


\section{Reflexiones finales}

En términos legales, el control y dominio por parte del Estado mexicano en materia hidráulica es un proceso histórico que durante el porfiriato se origina y se desarrolla en eventos extralegales. Con la llegada de la revolución de 1910, la "ficción legal" se corrigió con la Constitución de 1917. Los trabajos que hicieron los revolucionarios reforzaron aspectos que alimentaron los procesos de federalización, centralización y nacionalización realizados por la clase política porfirista al margen de la Constitución del 1857. En este sentido, las acciones legales durante el régimen del porfiriato solo fueron la preparación del terreno que luego harían los gobiernos de la revolución. El comentario que hizo Tocqueville sobre los efectos de la revolución francesa encaja perfectamente para el caso mexicano en materia hidráulica: "De lo que menos tuvo la Revolución fue de acontecimiento fortuito. Verdad es que cogió al mundo de improviso, pero, sin embargo, no era más que el complemento de un trabajo más largo, la conclusión repentina y violenta de una obra que habían trabajado diez generaciones de hombres" 75 .

A pesar de que los tres conceptos se desarrollaron simultáneamente, no significan lo mismo. Federalizar el agua en México durante el porfiriato fue expedir una serie de leyes con rango menor a la Constitución que permitió al gobierno federal tratar de ser el regulador en la gobernanza del agua. Con ello desplazó a los gobiernos locales (estatales y ayuntamientos) y a las comunidades de regantes privadas. Esto supuso generar una serie de políticas públicas que buscaban consolidar un proyecto nacional bajo la dirección del gobierno central.

Para lograrlo, el Estado centralizó aspectos de la política pública mexicana a través de una instancia federal. En el caso del agua, la creación de una burocracia encargada de tramitar las concesiones y dotaciones de agua reglamentadas por la legislación para uso exclusivo del gobierno federal. Esta burocracia se integró en una parte de la Secretaría de Fomento durante el porfiriato, hasta que llegó a formar un elemento importante de la burocracia federal durante los gobiernos surgidos de la revolución, con la formación de la Secretaría de Recursos Hidráulicos en 1946.

Para poder lograr una política federal y centralizada fue necesario que el Estado nacionalizara las aguas que estaban sujetas en buena medida a la acción de otras

75. Tocqueville, 2018, 48-49. soberanías y de los individuos. La forma de hacerlo fue recuperar y que se le reconociera el dominio eminente de los recursos que habían sido obtenidos a partir de un proceso de patrimonialización iniciado, por parte de los ayuntamientos y regantes, desde la colonia.

Uno de los elementos de la federalización del agua fueron los intentos de intervención en la organización social de los regantes. Al permitir que el gobierno federal fuera la autoridad encargada de reglamentar y legitimar el uso público y privado de las vías generales de comunicación o de las aguas federales, el reconocimiento de este dominio federal por parte de los regantes fue un apretón más a las tuercas del pretendido control estatal del agua. La intervención de un burócrata o de una persona que respondiera a las directrices de las instancias federales expresadas a través de los reglamentos era una facultad nueva que fue mejorándose con el paso del tiempo, aunque también fue cuestionada. Originalmente empezó en las corrientes fluviales declaradas federales como el río Nazas.

En el análisis de los reglamentos de agua sobre esta corriente, vimos cómo fue necesaria la intervención del Estado para mediar en el conflicto. También observamos cómo socialmente se reconoció esta mediación sin dejar de ser cuestionada. También distinguimos cómo participó la burocracia hidráulica en la elaboración de los reglamentos a través de los ingenieros de la Comisión del Nazas.

\section{BIBLIOGRAFÍA}

Aboites Aguilar, L. 1998: El Agua de la Nación. Una historia política de México (1888-1946). México D. F. (México), CIESAS.

Aboites Aguilar, L. 2009: La decadencia del agua de la nación. Estudio sobre desigualdad social y cambio político en México. Segunda mitad del siglo XX. México, D. F. (México), El Colegio de México.

Aboites Aguilar, L. y Estrada Tena, V. (comps.) 2004: Del agua municipal al agua nacional. Materiales para una historia de los municipios en México, 1901-1945. México, D. F. (México), CIESASComisión Nacional del Agua-Archivo Histórico del Agua-El Colegio de México.

Adams, Richard N. 1983: Energía y estructura. Una teoría del poder social. México, D. F. (México), Fondo de Cultura Económica.

AHA, Aguas Nacionales, caja 256, exp.2492. Reglamento de 1981.

Beltrán Bernal, T. 2017: La desecación del lago (Ciénega) de Chalco, http://polux.cmq.edu.mx/libreria/index.php?option=com_ docman\&view=download \& category_slug=docum investigacion\&alias=163-di0290141\&ltemid=189\&accept_license=1. [Consulta realizada el 25 de mayo de 2017]. 
Boehm, B. 2006: Historia ecológica de la Cuenca de Chapala. (México), El Colegio de Michoacán, Universidad de Guadalajara.

Boehm de Lameiras, B. 1994: "La desecación de la Ciénega de Chapala y las comunidades indígenas: el triunfo de la modernización en la época porfiriana", en Viqueira, C. y Torre, L. (Comps.), Sistemas hidráulicos, modernización de la agricultura y migración. Toluca (México), El Colegio Mexiquense-Universidad Iberoamericana, 341-384.

Boletín Oficial de la Secretaría de Fomento. 1909. México, Imprenta de la Secretaría de Fomento.

Camacho Pichardo, G. 1998: "Proyectos hidráulicos en las lagunas del Alto Lerma (1880-1942)", en Suárez Cortez, B. E. (Coord.), Historia de los usos del agua en México. Oligarquías, empresas y ayuntamientos (1840-1940). México, D. F. (México), CNA-CIESASIMTA, 229-280.

Castañeda, R. 2005: Las aguas de Atlixco. Estado, haciendas, fábricas y pueblos, 1880-1920. México, D. F. (México), Comisión Nacional del Agua-CIESAS-El Colegio de México.

Córdova, A. 1982: La ideología de la Revolución Mexicana. La formación del nuevo régimen. México, D. F. (México), Ediciones Era.

Dublán, M. y Lozano, J. M. 1876: Legislación Mexicana o colección completa de las disposiciones legislativas expedidas desde la Independencia de la República. México, D. F. (México), Tipografía de E. Dublán y compañía, tomo XXIV, 153.

Dublán, M. y Lozano, J. M. 1879: Legislación Mexicana o colección completa de las disposiciones legislativas expedidas desde la Independencia de la República. México, D. F. (México), Tipografía de E. Dublán y compañía, tomo XI, 254.

Dublán, M. y Lozano, J. M. 1890: Legislación Mexicana o colección completa de las disposiciones legislativas expedidas desde la Independencia de la República. México, D. F. (México), Tipografía de E. Dublán y compañía, tomo XIX.

Dublán, M. y Lozano, J.M. 1898: Legislación Mexicana o colección completa de las disposiciones legislativas expendidas desde la Independencia de la República. México, D. F. (México), Imprenta del Eduardo Dublán, tomo XXIV.

Galarza, E. 1941: La industria eléctrica en México. México, D. F. (México), Fondo de Cultura Económica.

García Martínez, B. 1992: "Jurisdicción y propiedad: una distinción fundamental en la historia de los pueblos de indios del México colonial". European Review of Latin American and Caribbean Studies / Revista Europea de Estudios Latinoamericanos y del Caribe, 53, 47-60. https://www.jstor.org/stable/25675553.

Glick, T. F. 1988: Regadío y sociedad en la Valencia medieval. Valencia (España), Del Cenia al Segura.

Guerra, F. X. 1988: Del antiguo régimen a la revolución. México, D. F. (México), Fondo de Cultura Económica.
Guzmán Ávila, J. N. 2002: "De cómo se descubrieron las tierras. Crónica de la desecación de la Ciénega de Zacapu", en Sánchez Rodríguez, M. (Coord.), Entre campos de esmeralda. La agricultura de riego en Michoacán. Zamora (México), El Colegio de Michoacán-Gobierno del Estado de Michoacán, 103-134.

Harris III, Ch. H. 1975: A Mexican Family Empire. The Latifundio of the Sanchez Navarro, Family 1765-1867. Austin (Estados Unidos de Norteamérica), University of Texas Press.

Huesbe Llanos, M. A. 1995: "La jurisdicción como atributo de la soberanía. El Derecho de apelación en última instancia o 'jus in extrema provocatione' y la concesión de la gracia en el estado moderno". Revista de Estudios Histórico-Jurídicos, 17, 337-358.

Hunt, R. C. 1997: "Sistemas de riego por canales: tamaño del sistema y estructura de la autoridad", en Martínez Saldaña, T. y Palerm Viqueira, J. (Edits.), Antología sobre pequeño riego. México, D. F. (México), Colegio de Posgraduados, 221-260.

Kroeber, C. B. 1994: El hombre, la tierra y el agua. Las políticas en torno a la irrigación en la agricultura de México, 1885-1917. México, CIESAS/IMTA.

Ley de aprovechamiento de aguas de jurisdicción federal (Del 19 de diciembre de 1910), 1911: Morelia (México), Talleres de la Escuela Industrial Militar Porfirio Díaz.

López Guardiola, S. G. 2012: Derecho administrativo II. Tlalnepantla (México), Red Tercer Milenio.

Maass, A. y Anderson, R. L. 1976:... and the Desert Shall Rejoice. Conflict, Growth, and Justice in Arid Environments. Cambridge, The MIT Press.

Maluquer de Montes, J. 1985: "La despatrimonialización del agua: movilización de un recurso natural fundamental", en García Sanz Á. y Garrabou, R. (Edits.), Historia Agraria de la España Contemporánea. Barcelona (España), Editorial Crítica, 279-289.

Marichal, C. 1988: "Políticas de Desarrollo Económico y Deuda Externa en Argentina, 1868-1880". Siglo XIX. Revista de Historia, 5, 89-125.

Martínez Saldaña, T. y Palerm Viqueira, J. (Edits.) 1997: Antología sobre pequeño riego. México, D. F. (México), Colegio de Posgraduados.

Medina Peña, L. 2010: "México 2010: hacia el porfiriato tardío", Nexos, http://www.nexos.com.mx/?p=14054. [Consulta realizada el 3 de mayo de 2017].

Modificaciones al reglamento de 15 de junio de 1895 sobre la distribución de las aguas del río Nazas. 1919, (México), Poder Ejecutivo Federal-Departamento de Aprovisionamientos GeneralesDirección de Talleres Gráficos.

Molina Enríquez, A. 1978: Los grandes problemas nacionales. México, D. F. (México), Era.

Moore, B. 1989: La injusticia: bases sociales de la obediencia y la rebelión, México, D. F. (México) UNAM. 
Ostrom, E. 2011: El gobierno de los comunes. La evolución de las instituciones de acción colectiva. México, D. F. (México), Universidad Nacional Autónoma de México-Fondo de Cultura Económica.

Ovalle Favela, J. 2007: "La nacionalización de las industrias petrolera y eléctrica". Boletín Mexicano de Derecho Comparado, 118, 169-191.

Palerm Viqueira, J. y Martínez Saldaña, T. (Edits.) 2000: Antología sobre riego. Organizaciones autogestivas. Vol. II. México, D. F. (México), Colegio de Postgraduados-Plaza y Valdés Editores.

Palerm Viqueira, J. y Martínez Saldaña, T. (Edits.) 2013: Antología sobre riego. Instituciones para la gestión del agua: vernáculas, alegales e informales. Montecillo, Texcoco (México), Colegio de Postgraduados-INIFAP-Universidad Autónoma de ChapingoMundi Prensa-IICA.

Palerm Viqueira, J. (Coord.) y Sandré, I., Rodríguez Haros, B. y Caletteet, N. D. (Edits.) 2004: Catálogo de Reglamentos de Agua en México. Siglo XX. AHA-CIESAS-CNA.

Plana, M. 1996: El reino del algodón en México. La estructura agraria de La Laguna (1855-1910). Monterrey (México), Universidad Autónoma de Nuevo León-Universidad Iberoamericana Plantel Laguna-Centro de Estudios Sociales y Humanidades de Saltillo.

Reglamento para la distribución de las aguas del río Nazas desde la presa de San Fernando en el estado de Durango, hasta la presa de la Colonia en el de Coahuila, 1919: México, D. F. (México), Poder Ejecutivo Federal, Departamento de Aprovisionamientos Generales-Dirección de Talleres Gráficos. http://www.torreon. gob.mx/archivo/pdf/libros/65\%20Reglamento\%20para\%20 la\%20distribuci\%C3\%B3n\%20de\%20las\%20aguas\%20del\%20 R\%C3\%AD0\%20Nazas.pdf. [Consulta realizada el 15 de septiembre de 2021].

Reglamento para la Distribución de las Aguas del Río Nazas en el Distrito de Riego de la Región Lagunera, Estados de Coahuila y Durango. 1939: Torreón (México), Archivo Municipal de Torreón, Biblioteca Digital. http://www.torreon.gob.mx/archivo/pdf/mondragon/154\%20Reglamento\%20para\%20la\%20 distribuci\%C3\%B3n\%20 de\%20las\%20aguas\%20 del\%20 r\%C3\%ADo\%20Nazas.pdf. [Consulta realizada el 15 de septiembre de 2021].

Reglamento Provisional para la distribución de las aguas del río Nazas desde la presa de San Fernando en el Estado de Durango, hasta la laguna de Mayrán en el de Coahuila. 1891: México, Oficina Tipográfica de la Secretaría de Fomento.

Román Jáquez, J. G. 2001: Del Aguanaval a Sierra Mojada. El conflicto de límites entre Durango y Coahuila, 1845-1900. México, Centro de Estudios Sociales y Humanísticos, A. C.

Romero Navarrete, L. 2007: El río Nazas y los derechos de agua en México: conflicto y negociación en torno a la democracia, 18781939. México D. F. (México), CIESAS- Universidad Autónoma de Coahuila.
Rouaix, P. 1929: Geografía del estado de Durango. México, D. F. (México), Talleres Gráficos de la Secretaría de Agricultura y Fomento.

Sánchez Rodríguez, M. 1993: "La herencia del pasado. La centralización de los recursos acuíferos en México". Relaciones, Estudios de Historia y Sociedad, 54, 21-41.

Sánchez Rodríguez, M. 2013: "Del antiguo régimen a la revolución. Notas sobre proyectos de irrigación en México antes y después de 1910". En Escobar Ohmstede A. y Butler, Mathew (coordinadores): México in Transition: New Perspectives on Mexican Agrarian History, Nineteenth and Twentieth Centuries, México, CIESAS, Institute of Latin American Studies, 261-286.

Sánchez Rodríguez, M. 2005: "El mejor de los títulos". Riego, organización social y administración de recursos hidráulicos en el Bajío mexicano. Zamora (México), El Colegio de MichoacánGobierno del Estado de Guanajuato.

Sandré Osorio, I. y Sánchez, M. (Coords.) 2011: El eslabón perdido. Acuerdos, convenios, reglamentos y leyes locales de agua en México (1593-1935). México, D. F. (México), CIESAS.

Saravia, E. 1909: Historia de la Comarca Lagunera y del Río Nazas. México, Imprenta de S. Gales.

Serra Rojas, A. 1977: Derecho Administrativo. Doctrina, Legislación y Jurisprudencia. México, Editorial Porrúa.

Tena Ramírez, F. 1982: Leyes Fundamentales de México, 18081967. México, Editorial Porrúa.

Tocqueville, A. 2018: El Antiguo Régimen y la Revolución. Madrid (España), Alianza Editorial.

Topete Pozas, 0. y Méndez Zárate, A. 2019: "Legislación estatal sobre los usos del agua en México: Una comparación entre los casos de Jalisco y Oaxaca, 1895-1905". Agua y Territorio, (14) 57-68, https://doi.org/10.17561/at.14.4388

Tortolero Villaseñor, A. 1995: De la coa a la máquina de vapor. Actividad agrícola e innovación tecnológica en las haciendas mexicanas: 1880-1914. México, Siglo XXI.

Vallarta, I. L. 1897: Los afluentes de los ríos navegables. Monterrey (México), Tipografía del Gobierno en Palacio, reimpresión.

Weber, M. 1983: Economía y sociedad. México, Fondo de Cultura Económica.

Wolfe, M. 2009: Water and Revolution: The Politics, Ecology and Technology of Agrarian Reform in "La Laguna", México, tesis doctoral, Universidad de Chicago, Chicago (Estados Unidos de Norteamérica).

Zuleta, M. C. 2000: "La Secretaría de Fomento y el fomento agrícola en México, 1876-1910: la invención de una agricultura próspera que no fue". Mundo Agrario. Revista de estudios rurales, 1 (1). 